\title{
Prevention of Sexual Abuse in Children with Mental Disability: A Systematic Literature Review
}

\author{
${ }^{1}$ Farlina, Mutia, ${ }^{2}$ Allenidekania \\ ${ }^{1,2}$ Master Program in the Faculty of Nursing, Universitas Indonesia, Indonesia
}

\begin{abstract}
Children with mental retardation have a 2.5 times higher risk of child sexual abuse (CSA) than other normal children. Mentally retarded children tend to experience verbal ability barriers in describing CSA cases. This study aims to describe the prevention of CSA by parents, teachers and health professionals, including the risk of CSA in mentally retarded children, need for CSA prevention, form of CSA prevention and effectiveness of CSA prevention in mentally retarded children. Method: PRISMA was used as a guide in compiling the systematic literature review based on the inclusion criteria to determine research articles, search strategies, and research findings. Four databases used in this research included Sage Journal, Ebsco Host, Scopus and Taylor \& Francis (Social Sciences \& Humanities Subject). Results: mentally retarded children have a higher risk of CSA than other normal children. The need for CSA prevention are felt by parents and teachers because of the lack of knowledge and ability to do prevention. The form of CSA prevention can be done with various efforts from various parties including parents. The CSA prevention program through role-play or training to face threatening situations is effective for mentally retarded children. It is expected that these findings will become a reference for nurses in ensuring the need for CSA prevention knowledge and ability for mentally disabled children.
\end{abstract}

Keywords: Child Sexual Abuse (CSA), prevention, mental health

\section{Introduction}

Mental retardation is a condition characterized by disruption or limited intelligence development and barriers to adaptive behavior (Salvador-carulla \& Reed, 2011). Children with mental retardation have IQs from 55 to 74 and lack of ability in memory capacity, language skills, imagination and ability in creativity (Kachalaki \& Faghirpur, 2015).

Based on a survey in 2015 , there were $6,050,725$ children aged 6 to 21 years who were identified as having limitations, and $3.4 \%$ of them had intellectual limitations or called mental retardation, which were managed by IDEA Part B in 50 states in the United States (Devos, Richey, \& Ryder, 2017).

* Corresponding author: Farlina, Mutia mutiafarlina5@gmail.com

Published online at http://IJDS.ub.ac.id/

Copyright (C) 2014PSLD UB Publishing. All Rights Reserved
Based on the Center for Data and Information of the Indonesian Ministry of Health (2014), in Indonesia the number of mentally retarded children aged 24-59 months reached $0.14 \%$ from 2010 to 2013.

Mentally retarded children have internalization and externalization disorders, decreased usefulness, lack of social skills and increased feelings of loneliness or likely being quiet. This triggers an increased chance of child sexual abuse (CSA) in children and adolescents with mental disabilities 2.5 times higher than those without mental disabilities (Helton, Gochez-kerr, \& Gruber, 2018).

Besides, mentally retarded children tend to be unable to recognize inappropriate relationships with others. They also may have limited verbal ability to describe CSA cases and to report violent behavior they may experience (Murphy, 2011 ; Hibbard, 2007).

CSA is a social problem that is increasingly worrisome. According to a survey in 2015 in the United States, the estimated incidence of CSA in children under 5 years 
(2011-2015) reached $8.4 \%$ of the 683000 children (U. S.Department of Health and Human Services, 2015). In fact, mentally retarded children have a higher risk of experiencing CSA than normal children, with a percentage ratio of 21\%:10\% (Helton, Gochezkerr, \& Gruber, 2018).

Most teachers in special schools state the importance of efforts to meet early sexual education needs for children and adolescents with mental disabilities. Besides high educational needs, they also reveal that there is inadequate sexual education conducted in schools. This relates to the lack of content taught and the absence of clear guidelines and appropriate tools in teaching sexual education to mentally retarded children and adolescents (Tsuda, Hartini, Hapsari, \& Takada, 2017).

Parents who have mentally retarded children have concern about the risk of CSA for their children. Parents realize that there is a risk of CSA in most mentally retarded children which comes from the closest persons of the child (Thomas, Kumar, \& Deb, 2014). Effective prevention of CSA is expected to reduce parents' anxiety about the independence of mentally retarded children in protecting themselves against alleged CSA (Kucuk, Platin, $\&$ Erdem, 2017).

A plenty of studies have explained the prevention of CSA that can be done in children with interventions, from the range of early age to school age that can improve children's knowledge and ability to protect themselves from the risk of CSA (S. Kim \& Kang, 2017; Zhang, Chen, Feng, \& Li, 2014).

A systematic review by Wals, Zwi, Woolferenden, and Shlonsky (2018) describes the CSA prevention in the form of school-based prevention program that can improve the protection of students. However, there are no studies that clearly explains the prevention of CSA specifically in children with mental retardation. Therefore, the researchers are interested to see how prevention of CSA in mentally disabled children is analyzed from related articles.

This present research aims to describe the CSA prevention in mentally retarded children which are done by parents, teachers and health professionals. The prevention being discussed includes the risk of CSA in mentally retarded children, the need for CSA prevention, form of CSA prevention and the effectiveness of CSA prevention in mentally retarded children.

\section{Methods}

\subsection{Sources of Data}

This literature review research employed the PRISMA method to describe the CSA prevention done by parents, teachers and the health professionals. The article search was conducted in October 2018 using electronic databases consisting of 4: Sage Journal, Ebsco Host, Scopus and Taylor \& Francis (Social Sciences \& Humanities Subjects). Then filtering articles consisted of 2 stages; first, from the titles and the abstracts, and second by reading the complete articles based on the inclusion criteria in this research.

\subsection{Inclusion Criteria}

The criteria included in the article search consisted of both quantitative and qualitative research articles describing the CSA prevention in mentally retarded children by parents, teachers and health professionals. The article publications were restricted from 2010 to 2018 written in English. Articles excluded from the criteria were that of systematic review, literature reviews, and meta-analysis.

\subsection{Search Strategy}

In the search of relevant articles, the researchers used a number of key words consisting of, "prevention", "child sexual abused", "disable", "child sexual abused prevention","and" , ,or", "intellectual disability", and "retardation mental children".

\section{Results}

There were 1130 articles found after entering the keywords. Of the 1130 articles, 55 articles were selected based on titles and abstracts. Then the second selection was done by reading the complete articles in accordance with the inclusion criteria. Afterwards, there were 8 articles obtained.

Mentally retarded children have a higher risk of CSA. To overcome this, various parties including nurses, genetic counselors, teachers and mothers as the closest people to children, need efforts to prevent CSA in 
mentally retarded children. Explanation of CSA prevention is presented through a collection of 8 related journals (6 quantitative articles and 2 qualitative articles) as follows.

\subsection{Risk of CSA in Mentally Retarded Children}

Based on the research Helton, Gochezkerr, \& Gruber (2018), hrough a survey of 5,873 children aged $0-17.5$ years from 83 states in the United States, it was found that approximately $22 \%$ of the children with mental retardation were suspected experiencing CSA. Mentally retarded children had a higher percentage of tendency to experience CSA than normal children with a percentage of $21 \%: 10 \%$. Further, female children with mental retardation had higher risk of CSA than the male ones. These mentally retarded children had 2.5 times higher chance of getting sexual violence compared those without intellectual disability.

This is because mentally retarded children have internalization and externalization disorders, decreased usefulness, lack of social skills and increased feelings of loneliness or tend to be quiet (Helton, Gochez-kerr, \& Gruber, 2018).

In another qualitative research, Gurol, Polat, \& Oran (2014) on 9 mothers who had mentally retarded children, it was revealed that most mothers were anxious because they knew that mentally retarded children had a risk of CSA due to the children's impaired developmental abilities.

This is in line with the research of Thomas, Kumar, \& Deb (2014) that investigated 60 mothers who had children with intellectual disabilities. The findings obtained were that the mothers $(53 \%)$ stated the possibility of the risk of violence at home, others $(40 \%)$ stated the possibility of risk obtained in a quiet place in an environment, and most of them $(86 \%)$ stated that violence could be obtained from the closest persons to their children.

\subsection{The Need for CSA Prevention}

Based on the analysis of this research, four out of the eight articles stated that parents especially mothers, teachers, nurses, or counselors of community social institutions stated that they needed efforts to prevent CSA in mentally retarded children who were at risk of experiencing this.
According to Tsuda, Hartini, Hapsari, \& Takada (2017), investigation, a study involving 130 female and male teachers who taught mentally retarded children (4-18 years) found that there were $(83.1 \%)$ teachers thought that sexual education in school was inadequate. This was due to the lack of materials regarding CSA prevention education that must be taught by teachers to mentally retarded children. Meanwhile, there were $(71.5 \%)$ teachers stated that the purpose of health education in schools was to teach children the appropriate knowledge.

Research by Gurol, Polat, \& Oran, (2014), found that 8 of 9 mothers as the participants who had mentally retarded children stated that they needed sexual education for their mentally retarded children. Most mothers stated that sexual education was expected to be provided by schools through seminars that mothers could also participate in. This was due to lack of information that the mothers had.

In line with the research conducted by Neill, Lima, Thomson, \& Newall (2015), on 6 mothers who had mentally retarded children, they found that the mothers explained that they needed information on explaining puberty or related-sexuality information to their children by considering cognitive ability and development of the children.

Further investigation on 38 counselors of mentally retarded children found that there were some of the parents, caregivers, and patients still asked about information regarding sexual abuse prevention in puberty as well as reproduction health for mentally retarded children (Murphy, Lincoln, Meredith, Cross, \& Rintell, 2016).

\section{3 Form of CSA Prevention}

Prevention can be done by parents especially mothers at home, by teachers at schools and even by health professionals or counselors. However, there are not many interventions described in detail in these 8 articles reviewed. Gurol, Polat, \& Oran's (2014) study found that the mothers stated they were always worried about the condition of their children by not leaving them alone, watching over them while sleeping at night, and watching over the interaction of their mentally retarded children their other normal children. The investigation by Tsuda, Hartini, Hapsari, \& Takada (2017) also found that the topics of sexual education taught by most teachers 75

Cite this as:

Farlina, Mutia, Allenidekania, Allenidekania. Prevention Child Sexual A Bused with Intellectual Disability. Indonesian Journal of Disability Studies (IJDS).2019: Vol. 6(1): PP 73-83. 
DOI:

$(66.9 \%)$ were how to maintain their own bodies (male and female) that can and should not be touched or seen by others as well as differences in gender.

From Y. Kim's (2016) research, the form of prevention were provided in the form of program or training administered to 3 mentally retarded children. It was a CSA prevention program that provided a training or simulation that taught self-protection skills to mentally retarded children. In that simulation, the children were being faced with particular threatening situations such as when there was someone asked them to undress, asked them to kiss her/him, and touched their sensitive parts.

\subsection{The Effectiveness of CSA Prevention in Mentally Retarded Children}

The implementation of CSA prevention has a positive impact in improving the knowledge and ability of mentally retarded children in preventing them from the risk of CSA. CSA prevention is also useful in providing information to parents in collaborating with schools and health professionals.

The finding from the research conducted by Kucuk, Platin, Erdem, (2017) showed the data that CSA prevention program intervention that was performed in 15 mentally retarded children with mild mental retardation (9 males, 6 females) aged 10-14 years was effective in reducing the parents' anxiety on their mentally children's ability in protecting themselves against alleged CSA. The prevention was done by increasing children's knowledge of sensitive parts of the body that need to be maintained, good and bad touches, how to verbally express the word "no" when experiencing unpleasant situations, how to protect themselves from strangers and report that unpleasant experience to the closest persons. Cooperation with parents and reinforcement at home are expected to increase the effectiveness of CSA prevention education.

Another research by Y. Kim (2016) also revealed that the prevention given in the form of program or training administered to 3 mentally retarded children in the form of a simulation or role play was effectively used in teaching self-protection skills to mentally retarded children. There was an increase in the ability of mentally retarded children to verbally agree or reject certain situation by saying "no", as well as the ability to leave or to report an unpleasant situation to the closest persons.

\section{Discussion}

In compiling this literature review, there were analyses from 8 articles relating to prevention of child sexual abuse (CSA) in mentally retarded children, which were traced to relevant articles from 2010 to 2018. The results found from these articles explained the risks, the need, the form and effectiveness of CSA prevention in mentally retarded children. Furthermore, these various articles used varied methods such as cross sectional, quasi experiment, qualitative, and A Multiple Probe across research.

There were four cross sectional methods criticized based on Joanna Briggs Institute (JBI) guidelines. All of them described the subjects of research and background of the respondents in detail consisting of respondent characteristics of the mentally regarded children by setting the age range, the characteristics of the mentally retarded children's mothers, teachers who taught mentally retarded children and the characteristics of counselors who were included in the research. In these four articles, the inclusion criteria were explained, but the exclusion criteria in the sampling were not (Helton et al., 2018; Tsuda et al., 2017).

The analysis carried out in the articles uncovered that prevention of CSA in mentally retarded children requires the collaboration of various parties including parents as the closest persons to children, teachers, counselors and health professionals. This is in line with the findings of Karia, Polat, and Oran (2014) in evaluating the views of mothers who had mentally retarded children related to the provision of sexual education and protection for children from possible abuse.

The findings of this research are guidelines for nurses, rehabilitation centers and schools to prioritize sexual education for mentally retarded children, to fulfill lack of information by families and to increase awareness of this topic. This is consistent with the research of Zang, Chen, Feng, \& Li (2014) stating that the key success of CSA prevention was in collaboration and attention from various parties closest to preschoolers including 
parents, teachers, social workers, policy makers and public in general.

Forms of prevention done by mothers at home were less explored in these articles. There are still very few of research exploring experiences of mothers in preventing CSA and obstacles they find at home to prevent CSA. One of the eight articles in this research, Gurol, Polat, \& Oran (2014), informed that there were some mothers expressed their anxiety over their children by not leaving them alone, watching over them while sleeping at night, and keeping an eye the interaction between their mentally retarded children with their other normal children.

Of the eight articles, 2 articles found the intervention given through training or role play by positioning the mentally retarded children in particular threatening situations were effective in increasing the knowledge and ability of mentally retarded children to protect themselves from the risk of CSA. CSA prevention is effective in reducing parents' anxiety over how their children can protect themselves from alleged CSA. Collaboration with parents and reinforcement at home are expected to increase the effectiveness of CSA prevention education (Y. Kim, 2016; Kucuk, Platin, \& Erdem, 2017).

This is in accordance with the research of Kim and Kang (2017), informing that CSA prevention program for children is an effective method of improving the ability of children to recognize forms of CSA prevention, including knowledge and behavior of self-protection.

\section{Strange \& Limitation}

In reviewing the articles related to the prevention of CSA in mentally retarded children, various results were found in terms of various efforts in increasing the independence and ability of mentally retarded children to protect themselves. However, there was also limitation of this research, namely the heterogeneity of methods, populations, areas, and the results of articles that were difficult to make comparisons among the great impacts of each of the research articles.

\section{Conclusion}

In the research development so far, there have not been many studies related to prevention of CSA specifically carried out in mentally retarded children. The conclusions of this review system are drawn into four topics related to the prevention of CSA in mentally retarded children. First, mentally retarded children are children with developmental disorders who have a high risk of CSA due to their developmental disorders, especially verbal communication in expressing the insecurity they may experience.

Second, the need for information on prevention of CSA is felt by various parties including parents especially mothers as the closest person to children, and teachers who think that the existing content of information regarding CSA prevention is still inadequate. Third, the forms of CSA prevention are varied, including supervision by mothers at home, teaching of CSA prevention conducted at schools and CSA prevention training conducted by counselors or nurses.

Fourth, the CSA prevention program carried out for mentally retarded children through role-play or training on how to face threatening situations is effective for mentally retarded children.

\section{References}

Devos, Richey, \& Ryder, (2017). 39th annual report to congress on the implementation of the individuals with disabilities education act, 2017. washington : U.S. department of education.

https://www2.ed.gov/about/reports/annual/osep/ 2017/parts-b-c/39th-arc-for-idea.pdf

Gurol, A., Polat, S., \& Oran, T. (2014). Views of mothers having children with intellectual disability regarding sexual education: A Qualitative. Journal of Sexual Disability. 123133. https://doi.org/10.1007/s11195-014-93388

Helton, J. J., Gochez-kerr, T., \& Gruber, E. (2018). Sexual abuse of children with learning disabilities. Journal of Child Malteratment 23(2),157-165.

https://doi.org/10.1177/1077559517733814

Hibbard, \& Desch. (2007). Maltreatment of children with disabilities. Journal of Pediatrics. https://www.ncbi.nlm.nih.gov/pubmed/1747310 5 
Kachlaki, \& Faghirpour. (2014). The effect of play therapy in the development of cognitive skills, social and motor educable mentally retarded students. Jurnal UMP Social Sciences and Technology Management. http://jsstm-ump.org/2015

\%20Volume\%203,\%20Issue\%203/406-411.pdf

Kim, S., \& Kang, K. (2017). Effects of the child sexual abuse prevention education (C-SAPE) program on south korean fifth-grade students, competence in terms of knowledge and selfprotective behaviors. The Journal of School Nursing.33(2),123-132.

https://doi.org/10.1177/1059840516664182

Kim, Y. (2016). Evaluation of a sexual a bused prevention program for children with intellectual disabilities. The Journal of Behavior Intervention. 209,195-209. https://doi.org/10.1002/bin

Kucuk, S., Platin, N., \& Erdem, E. (2017). Increasing awareness of protection from sexual abuse in children with mild intellectual disabilities: An education study Applied Nursing Research.

https://doi.org/10.1016/j.apnr.2017.10.016

Murphy, C., Lincoln, S., Meredith, S., Cross, E. M., \& Rintell, D. (2016). Sex education and intellectual disability: Practices and insight from pediatric genetic counselors. Journal of Genetic Counseling, 552-560. https://doi.org/10.1007/s10897-015-9909-6

Murphy, N. (2011). Maltreatment of children with disabilities: The breaking point. Journal of Child Neurology 26(8), 1054-1056.

https://doi.org/10.1177/0883073811413278

Neill, J. O., Lima, S., Thomson, K., \& Newall, F. (2015). The experiences and needs of mothers supporting young adolescents with intellectual disabilities through puberty and emerging sexuality. Research and Practice in Intellectual and Developmental Disabilities, $0(0), 1-11$.

https://doi.org/10.1080/23297018.2015.107734 2

Pusdatin, Republic of Indonesia Ministry of Health. (2014). Grooming Disability in Children. Retrieved 16 November 2018. www.depkes.go.id/download.php?file=downloa d/pusdatin/infodatin/infodatin...pdf

Salvador-carulla, L., \& Reed, G. M. (2011). Intellectual developmental disorders : towards a new name, definition and framework for " mental retardation / intellectual disability" in ICD-11. World psychiatry: official journal of the World Psychiatric Association WPA https://doi.org/10.1002/j.20515545.2011.tb0004 5.x

Thomas, Kumar, \& Deb. (2014). Abuse of intellectually disabled children risks as perceived by the mothers. Social Science International.. http://remote-lib.ui.ac.id

Tsuda, S., Hartini, S., Hapsari, E. D., \& Takada, S. (2017). Sex education in children and adolescents with disabilities in yogyakarta, indonesia from a teachers' gender perspective. Asia Pacific Journal of Public Health. 7-10. https://doi.org/10.1177/1010539517702716

U. S.Department of Health and Human Services. (2015). Child maltreatment 2015.https://www.acf.hhs.gov/sites /default /files /cb/cm2015.pdf

Walsh, K., Zwi, K., Woolfenden, S., \& Shlonsky, A. (2018). School-based education programs for the prevention of child sexual abuse : A cochrane systematic review and, meta analysis. Research on Sosial Work Practice. 28(1),33-55.

https://doi.org/10.1177/1049731515619705

Zhang, W., Chen, J., Feng, Y., \& Li, J. (2014). Evaluation of a sexual abuse prevention education for chinese preschoolers. Research on Sosial Work Practice. 24(4), 428-436. https://doi.org/10.1177/1049731513510409 
IJDS 2019; Vol. 6 No. 1, May 2019, pp. 73-83

ISSN: $2355-2158$

DOI:

Table. 1 Characteristics of articles

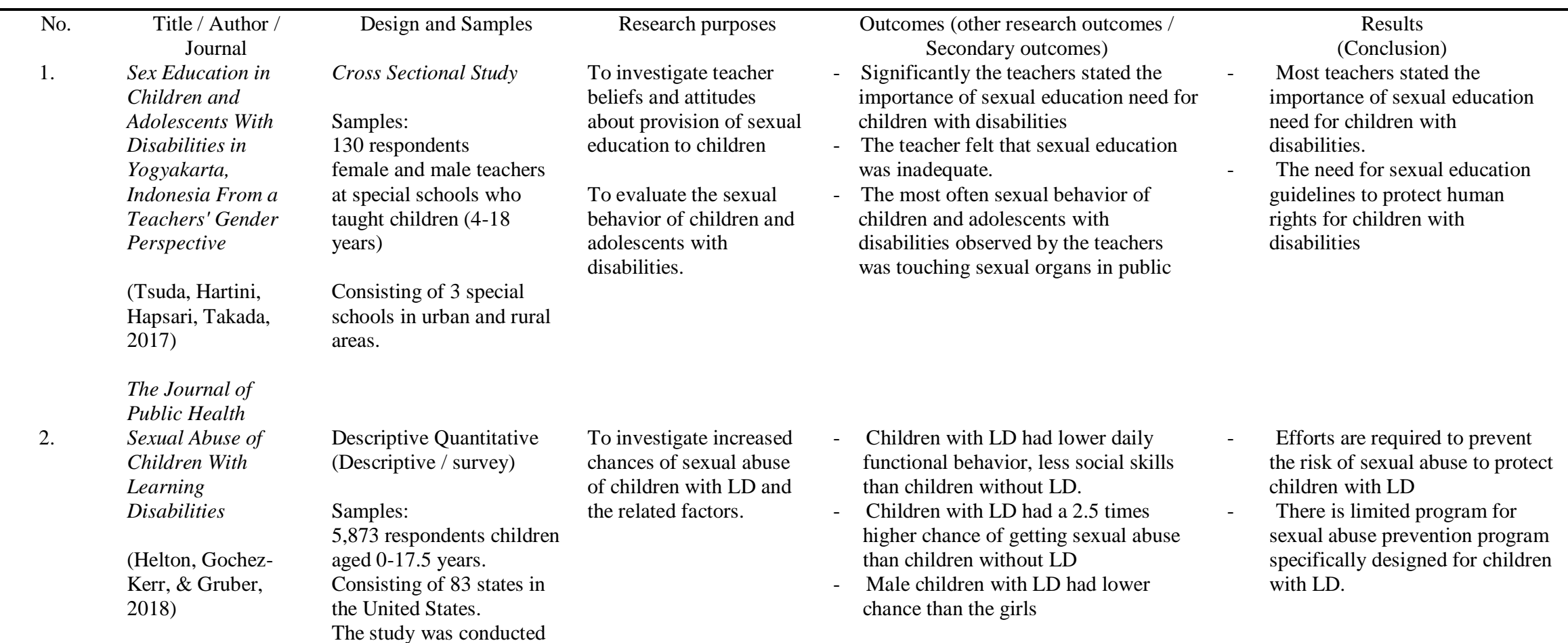

y was conducted

Maltreatment

for 20 months 
3.

$\begin{array}{ll}\begin{array}{l}\text { Evaluation Of a } \\ \text { Sexual Abuse }\end{array} & \text { A Multiple Probe across } \\ \text { Prevention } & \text { Samples: } \\ \text { For Children With } & \text { The participants were 3 } \\ \text { Intellectual Program } & \text { female elementary } \\ \text { Disabilities } & \text { students with LD }\end{array}$

(Kim, Yu-Ri, 2016)

The Journal of

Behavior

Intervention

\section{Increasing}

Awareness of

Protection From

Sexual Abuse

In Children With

Mild Intellectual

Disabilities: An

Education Study

(Kucuk, Platin,

Erdem, 2017)

Journal of Applied

Nursing Research
Sampling technique :

Purposive sampling

Criteria:

- Mild to medium mental retardation

- The $4^{\text {th }}$ to $6^{\text {th }}$ graders

- Verbal skills were

quite good

- Never received prior training

- Approved by parents Semi Experimental study

(Pre Post one intervention group)

Samples:

15 mildly retarded

children aged 10-14 years

Sampling technique:

Convenience sampling

Data collection:

Opinions from

parents and children

with 23 interview

questions

- $\quad$ Reading the results of writing stories,

pictures, and

compiling story

books with expert

opinions
To evaluate the effectiveness of sexual abuse prevention program for mentally retarded children
- $\quad$ First the participants (P1), (P2) and (P3) experienced an increase overall compared to those before the intervention.

- $\quad$ In the first session, P3 in was able to refuse and to leave the situations given, but he did not report immediately.
Parents expressed their concerns to expose their children to dangerous situations.

- Conclusion: sexual abuse prevention program with role play is effective to teach selfprotection skills to children with mental retardation.
The children's knowledge about CSA prevention was significantly higher after intervention

To determine the knowledge of mentally retarded children about how to prevent sexual

abuse about sensitive parts of body, good and

bad touches, saying "no" to protect

themselves from strangers and reporting cases of sexual abuse.
Educational program about CSA prevention needs to be

implemented by considering the cognitive ability of mentally retarded children

Cooperation with parents, reinforcement at home are expected to increase the effectiveness of CSA prevention education

- CSA prevention is effective in reducing parents' concerns about the independence of mentally retarded children in protecting themselves against alleged CSA. 


$\begin{array}{ll}\text { Views of Mothers } & \text { Focus Group (Qualitative } \\ \text { Having Children } & \text { Study) } \\ \text { with Intellectuals } & \\ \begin{array}{ll}\text { Disability Regarding } \\ \text { Sexual Education: A }\end{array} & \begin{array}{l}\text { Participants: } 9 \text { mothers } \\ \text { with mentally retarded }\end{array}\end{array}$

Sexual Education: A

Qualitative

Study

(Gurol, Polat, \&

Oran, 2014)

Journal of Sexual

Disability

6.

The experiences and needs of mothers supporting young adolescents with

intellectual

disabilities through

puberty and

emerging sexuality

(Neil, J et al., 2015)

Research And

Practice In

Intellectual And

Developmental

Disabilities

7. Abuse Of

Intellectually

Disabled Children

Risks As Perceived

By The Mothers

Thomas, Kumar, \&

Deb, 2014)

Social Science

International

children aged 7-18 years.

Sampling technique:

Convenience sampling

Data retrieval :

Interviews with semi-

structured questions

Study

Sample:

6 mothers with mentally

retarded adolescents (11-

15 years old)

Data collection: semi-

structured interviews

with mild and medium

mentally disabled children

(IQ < 70)

Mothers with mentally

retarded children and

physical limitations

Quantitative Descriptive

Qualitative

Samples:

60 mothers with mentally

retarded children; 30

years)
Qualitative Descriptive

Inclusion criteria: Mother

Exclusion criteria:

women and 30 men (10-23

Cite this as:

Farlina, Mutia, Allenidekania, Allenidekania. Prevention Child Sexual A Bused with Intellectual Disability. Indonesian Journal of Disability Studies (IJDS).2019: Vol. 6(1): PP 73-
To evaluate the views of mothers who have mentally retarded children about providing sexual education for children and protecting children against possible abuse

To get description of mother's experiences and needs in supporting mentally retarded

adolescents during

puberty and the

emergence of sexuality

To understand the perception of mothers about the risk of abuse (physical, sexual, or neglect) in mentally retarded children
- Most of the mothers stated that mentally disabled children were at risk of abuse. - there were still mothers who thought that there was no possibility of mentally disabled children at risk of abuse

- Some of the mothers stated there was possibility of abuse at home, and in a quiet place outside home

Most of the mothers stated that abuse can face puberty and providing information support for sexual

education can help mothers fully accept their adolescents with mental retardation.
Preparing parents with adolescents to
Mentally retarded children have a higher risk of abuse (physical,

sexual or neglect), thus a special training or education is needed for parents who have disabled children as a method of controlling behavior and parenting methods in

accordance with mentally retarded children. sexual education for their mentally

retarded children and sexual education

seminars that the mothers could

felt anxious over that

information on how to explain puber

mentally retarded children by considering

their cognitive ability and development.

81
Most mothers knew that mentally
These findings are considered as a guideline for nurses,

rehabilitation centers and schools to prioritize sexual education for mentally retarded children, to

fulfill the lack of information by

families and to increase

awareness of this topic. 
IJDS 2019; Vol. 6 No. 1, May 2019, pp. 73-83

ISSN: $2355-2158$

DOI:

\begin{tabular}{|c|c|c|c|c|c|}
\hline & & $\begin{array}{l}\text { Sampling technique: } \\
\text { Purposive sampling }\end{array}$ & & be done by the closest persons. & \\
\hline 8. & $\begin{array}{l}\text { Sex Education and } \\
\text { Intellectual } \\
\text { Disability: Practices } \\
\text { and Insight from } \\
\text { Pediatric Genetic } \\
\text { Counselors } \\
\text { (Murphy, C. et al., } \\
\text { 2016) } \\
\text { Journal of Genetic } \\
\text { Counselors }\end{array}$ & $\begin{array}{l}\text { Data collection : } \\
\text { Semi-structured } \\
\text { questionnaire } \\
\text { Pilot Study } \\
\text { Samples: } \\
38 \text { genetic counselors with } \\
\text { mentally retarded patients } \\
\text { (9-17 years old) } \\
\text { Sampling technique : } \\
\text { purposive sampling } \\
\text { Data collection } \\
\text { : survey with } 25 \\
\text { questionnaires } \\
\text { Inclusion criteria } \\
\text { - Genetic counselors who } \\
\text { had counseling } \\
\text { experiences for mentally } \\
\text { retarded children }(9-17)\end{array}$ & 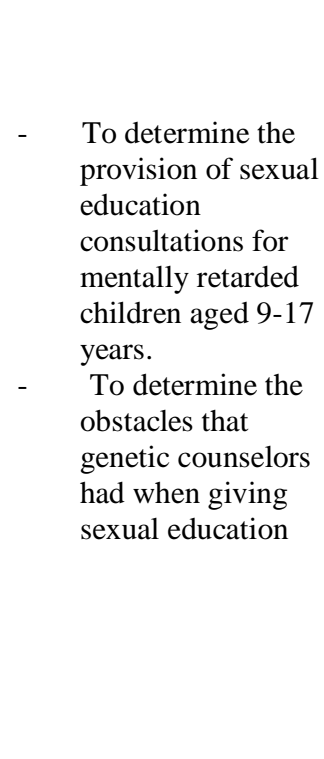 & $\begin{array}{l}\text { - The genetic counselors stated that } \\
\text { parents, caregivers, or patients asked for } \\
\text { information about sexual abuse } \\
\text { prevention, puberty and reproduction } \\
\text { health. } \\
\text { - Professionals that should provide } \\
\text { sexual education for psychiatrists, } \\
\text { nurses, school educators and genetic } \\
\text { counselors } \\
\text { - Almost all respondents experienced } \\
\text { obstacles in counseling, such as lack of } \\
\text { sexual education counseling training. }\end{array}$ & $\begin{array}{l}\text { - Parents, caregivers or mentally } \\
\text { retarded children need information } \\
\text { on sexual education, puberty, } \\
\text { reproduction health and sexual } \\
\text { abuse prevention }\end{array}$ \\
\hline
\end{tabular}


DOI:

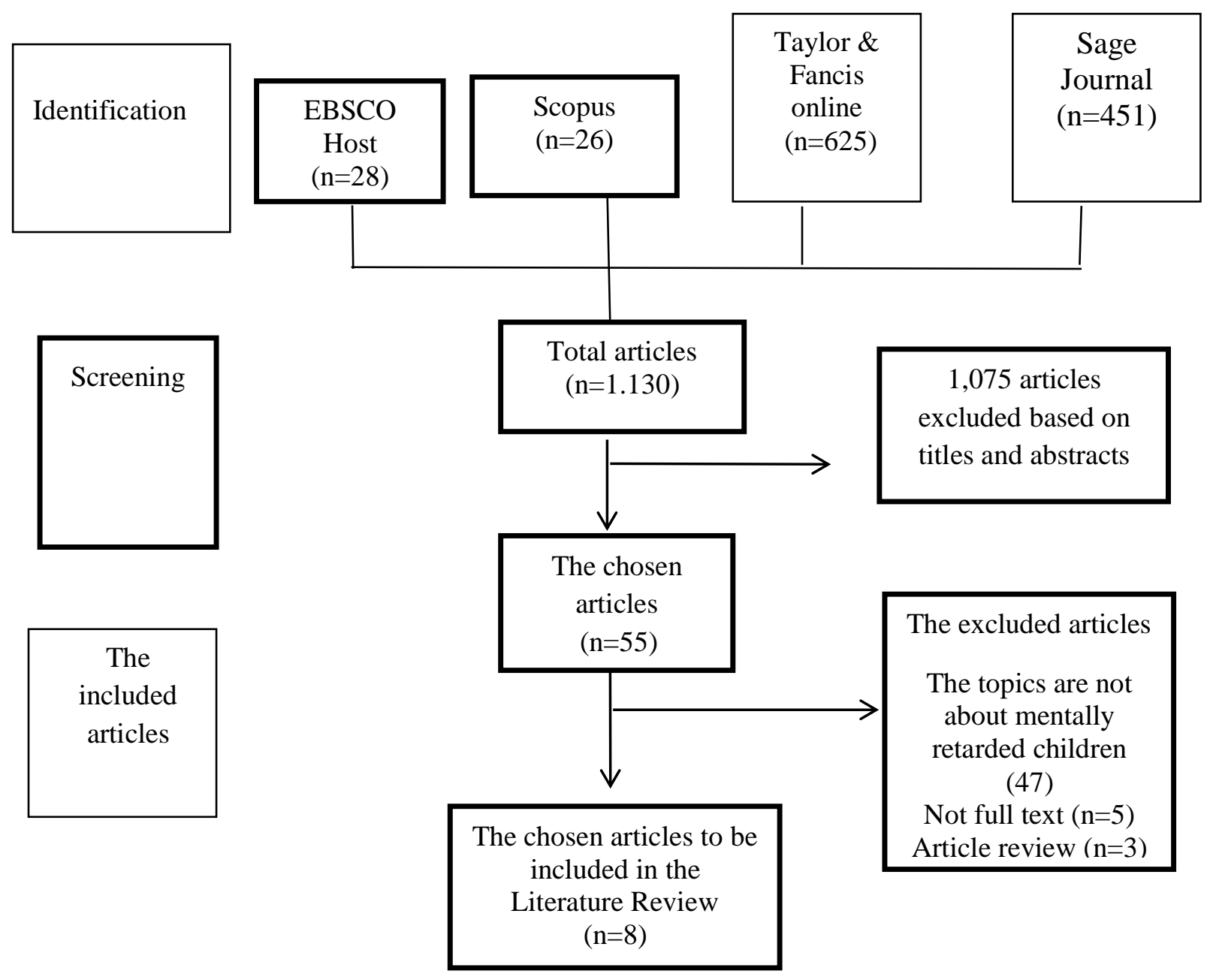

Figure 1. Article Selection Flowchart 